\title{
PROCESSOS DE (DES)LEGITIMAÇÃO LINGUÍSTICO-COGNITIVA: NOTAS SOBRE O CAMPO DAS PATOLOGIAS
}

Edwiges Maria Morato ${ }^{1}$

RESUMO: Para desvelar certos processos de (des)legitimação linguística e cognitiva no campo das patologias neurolinguísticas, gostaríamos de definir os objetos da breve reflexão deste artigo: o escopo do termo afasia e o discurso sobre a doença de Alzheimer. Em uma e em outra encontram-se comprometidas, de várias formas, as capacidades comunicativas, sociocognitivas e interacionais dos indivíduos. Estigmatizadas de um modo ou de outro, ambas as patologias são marcadas por um incremento de inequidade de diversas ordens que se estabelecem em diferentes âmbitos da vida social. O conhecimento sobre os processos a que a linguagem faz referência abre espaço para mudanças epistêmicas e uma composição mais dinâmica de forças no jogo social.

Palavras-chave: (Des)legitimação. Patologias. Cognição social.

\section{Processes of linguistic-cognitive (de)legitimation: notes on the field of pathologies}

ABSTRACT: In order to discuss certain processes of linguistic and cognitive (de)legitimation in neurolinguistic pathologies, we would like to define the object of this short reflection: the scope of the aphasia term and the discourse on Alzheimer's disease. It is worth noting that these two pathological contexts are marked by the growth of several orders of iniquity in

${ }^{1}$ Universidade Estadual de Campinas - Campinas (SP), Brasil. E-mail: edwiges@iel.unicamp.br DOI: $10.1590 / C C 0101-32622018183678$ 
different social life spheres. The knowledge of processes to which the language refers opens space for epistemic changes and for a greater dynamic of social forces in the social game.

Keywords: (De)legitimation. Pathologies. Social cognition.

\section{INTRODUÇÃO}

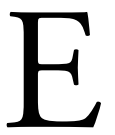

m geral, no campo dos estudos socioantropológicos, fala-se de "legitimidade", termo de fato polissêmico, quando um determinado ator (ou ação) encontra-se em conformidade com determinados valores, padróes e regimes socialmente admitidos ou impostos por determinados indivíduos e grupos providos de autoridade, poder, prestígio. Tal consonância diz respeito a critérios tais como senso de adequação, coesividade epistêmica, pertencimento socioeconômico, dominação (WEBER, 2009).

Contudo, com abordagens mais dinâmicas e recentes do conceito, a legitimidade pode ser compreendida como aquilo que se produz a partir de um "processo construtivo e deliberativo de conquista de reconhecimento em contexto" (ALBUQUERQUE, 2011, p. 106). Como podemos observar, essa acepção toma novos ares conceptuais, afastando-se das teorias políticas clássicas que o concebem em termos de mera conformidade relativa a um poder (em geral, institucional) estabelecido. Tal perspectiva, que realça a náo unilateralidade do conceito, afirma que "a legitimidade não se pressupóe, conquista-se" (ALBUQUERQUE, 2011, p. 106).

Legitimidade é, pois, não apenas imposição e subordinação, mas conquista e mudança. Trata-se de um conceito relacional que salienta princípios de um empreendimento racional no âmbito do jogo social; assim sendo, envolve estruturas ou esquemas de expectativa, representação de experiências de vida em sociedade, negociaçáo, tomada de consciência, reflexividade.

São os chamados "processos de legitimação" que reconhecem, validam, legalizam e qualificam um ato qualquer, um processo social, 
uma dada forma de compreender a realidade, um dado sistema de crença ou ideologia — de modo a torná-los legítimos e consensuais (BOBBIO, 2004) para uma (dada) comunidade ou parcela da populaçáo. Os processos que deslegitimam grupos, ações e indivíduos são, dessa maneira, dialeticamente, outra face desse processo que envolve, de algum modo, negociação e disputa entre os atores sociais.

O campo linguístico, como sabemos, tem atuado nos processos de legitimação da competência comunicativa e da norma-padrão de uma língua, na valorização ou desvalorização de variáveis linguísticas, na aproximação ou diferenciação entre o normal e o patológico, na discussão sobre a constituição e a sedimentação de uma língua nacional, na decisão sobre o que é ou náo politicamente correto na linguagem, etc. Tanto o metadiscurso científico quanto as práticas linguísticas cotidianas constituem-se como lugares de (des)legitimaçáo social da linguagem e dos processos afeitos a ela, como têm nos mostrado tantos estudiosos da área (VAN DIJK, 2010; FALCONE, 2011; BAGNO, 2003; RAJAGOPALAN, 2000; MORATO; BENTES, 2002, dentre muitos outros).

Formas de legitimação e deslegitimação da língua e dos falantes são vinculadas à maneira como são concebidos os elementos que integram o sistema nocional da Linguística (como língua, língua nacional, competência linguística, por exemplo) e aqueles que constituem seu objeto de forma irredutível (como o contexto social, as interaçóes humanas, os processos cognitivos).

Para desvelar certos processos de (des)legitimação linguística e cognitiva no campo das patologias neurolinguísticas, gostaríamos de definir os objetos da breve reflexão deste artigo: o escopo do termo afasia e o discurso sobre a doença de Alzheimer. Em uma e em outra encontram-se comprometidas, de várias formas e em diferentes graus de severidade, as capacidades comunicativas, interacionais, sociocognitivas, ocupacionais. Estigmatizadas de um modo ou de outro, ambas as patologias são marcadas por um incremento de inequidade de diversas ordens que se estabelecem em diferentes âmbitos da vida social.

Dada a nossa tradição logocêntrica, como falar em conquistas, mudanças e negociaçóes envolvendo atores sociais com distintos papéis e estatutos na disputa pela competência comunicativa e cognitiva "legítima", como no caso das patologias da linguagem e da cognição? 
Como distinguir, nos processos de (des)legitimação das formas comunicativas de pessoas com afasia e com doença de Alzheimer, aquilo que deriva de uma formulação utópica (a respeito da linguagem, por exemplo) e aquilo que deriva simplesmente da intolerância e do preconceito?

\section{AFASIA E DOENÇA DE ALZHEIMER: A LINGUAGEM E A COGNIÇÃO SOB TENSÃO}

Tratemos, nesta seção, de definir brevemente a afasia e a doença de Alzheimer. Em outro texto, assim definimos esses dois contextos nosológicos (MORATO, 2016, p. 583-584):

1. As afasias são definidas como alterações de linguagem oral e ou escrita (anomias, parafasias, agramatismos, distúrbios fonoarticulatórios, etc.) decorrentes de lesão mais ou menos circunscrita no Sistema Nervoso Central em função de acidentes vasculares cerebrais, traumatismos cranioencefálicos ou tumores. As afasias [...] podem ser acompanhadas por outros sintomas neurológicos e neuropsicológicos, como as hemiplegias, as discalculias, as apraxias e as agnosias.

2. No campo dos estudos neurocognitivos, entende-se em linhas bem gerais que a Doença de Alzheimer evolui em três estágios: leve, no qual os problemas mnésicos são constantes, assim como certa desorientação das funçóes executivas cotidianas e dificuldades sutis de evocação de palavras e manipulação de regras pragmáticas e sociocognitivas que presidem a utilização da linguagem nos mais variados contextos de uso; moderado, no qual os problemas mnésicos passam a ser incapacitantes, seguidos de crescente desorientação temporal-espacial e de problemas de linguagem frequentes (confabulação, circunlóquios, anomia, fala agramatical, etc.) e prontamente perceptíveis nas atividades cotidianas; severo, no qual a memória, a consciência e outros processos cognitivos encontram-se gravemente alterados e a linguagem apresenta-se sensivelmente comprometida em todos os seus níveis - formais e discursivos de constituição. 
De um ponto de vista neurolinguístico, a afasia tem sido caracterizada tradicionalmente pela carência metalinguística, isto é, pela alteração da capacidade de realizar operaçóes linguísticas (como a categorizaçáo) por meio das quais interpretamos e construímos sentidos e fazemos referência ao mundo por meio da linguagem. A dificuldade predicativa e a de evocar e processar palavras seriam exemplos dessa alteração. Essa característica da linguagem afásica explicaria fenômenos como a anomia, as parafasias de diversas naturezas linguísticas, os titubeios e as hesitaçōes, as alterações gramaticais, a fala off topic (isto é, aquela que se caracteriza por uma dificuldade de reconhecer, manter ou gerenciar o tópico discursivo).

A segunda patologia, doença de Alzheimer, tem sido tradicionalmente associada à perda da memória e da consciência, razão dos sintomas linguísticos e cognitivos apresentados em graus variados de severidade pelos indivíduos diagnosticados, como desorientação temporal e espacial, lacunas ou falhas mnêmicas variadas (memória episódica, autobiográfica, semântica, cultural etc.), infração de regras pragmáticas que orientam os atos comunicativos nas mais variadas circunstâncias de uso social da linguagem e da dinâmica interacional de uma forma geral, alteração da faculdade crítica, fala off topic, dificuldade de reconhecer intenções comunicativas e realizar inferências de forma relevante para os propósitos discursivos e interacionais.

Vale notar que, de um modo ou de outro, mesmo os indivíduos sem comprometimento neurocognitivo podem confrontar-se com fenômenos como os acima descritos nas mais variadas práticas discursivas e sociais cotidianas, o que não permite tomar ambas as patologias — a não ser ao arrepio do bom-senso - como meras excrescências em relação ao que é tido como normal na linguagem e na cognição. Assim, podemos admitir que não apenas as condiçóes neuropsicológicas e neurolinguísticas específicas indicariam o caráter patológico das produçôes e interpretações linguísticas, mas processos de (des)legitimação de ordem sociocultural associados ao que se entende por bem falar, bem pensar, bem agir.

Processos de (des)legitimação da competência comunicativa de indivíduos com afasia e doença de Alzheimer estão, vale dizer, associados a determinados escopos dos termos da afasia e da doença de Alzheimer, 
em especial os atinentes a modelos linguísticos fortemente estruturalistas e a modelos neuropsicológicos estritamente biomédicos, muito judiciosos em relação ao que é considerado normal ou desviante na linguagem e na cognição. Exemplares de uma visão normativista ou idealizada observada no enfrentamento dessas patologias, centrados em dicotomias clássicas (normal versus patológico, corpo versus mente, natureza versus ambiente etc.), podem ser encontrados tanto no metadiscurso científico quanto nos protocolos de avaliação e diagnóstico clínico, dos quais derivam práticas médicas e terapêuticas, Programas de Saúde, políticas de inclusão social etc.

Não é à toa que ambas são, via de regra, simbolicamente concebidas em termos de combate, heroísmo, prisão, morte ou luto, como demonstram estudos voltados para a conceptualizaçáo de doenças por meio de enquadres conceptuais como metáforas, frames, modelos cognitivos etc. (ver, por exemplo, FOX, 1989; SONTAG, 2007; GEORGE; WHITEHOUSE, 2014; BLEAKLEY, 2016; ZIMMERMANN, 2017).

Se, por razões distintas, a afasia e a doença de Alzheimer deixam a linguagem e a cognição "sob tensão" (para usar a expressão de Porter, 1993) é porque afetam a linguagem, a racionalidade, a cognição, a cooperação social — capacidades tipicamente humanas. São, em geral e de diversas maneiras, em função do desprovimento dessas capacidades, muito mal "toleradas" em termos socioculturais. A ensaísta norte-americana Susan Sontag (2007) bem focalizou a questão da intolerância radial de certas patologias no livro A Doença como Metáfora. Entre outras coisas, a autora analisa os efeitos de sentido da palavra portador (de alguma doença altamente estigmatizante, como o câncer), capaz de legitimar certo metadiscurso científico (a respeito da etiologia e da erradicação da doença, por exemplo) e deslegitimar determinadas condiçóes ou reaçóes daqueles que convivem com ela (neste caso, as açóes de deslegitimação atingiriam não apenas o doente, mas também os seus próximos, por exemplo). Uma das metáforas de que Sontag se serve é a da doença como um "mau passaporte":

Todos que nascem têm uma dupla cidadania, no reino dos sãos e no reino dos doentes. Apesar de todos preferirmos só usar o passaporte bom, mais cedo ou mais 
tarde nos vemos obrigados, pelo menos por um período, a nos identificarmos como cidadãos desse lugar (SONTAG, 2007, p. 11).

Dizer que as afasias impedem a comunicação por serem uma "alteração da capacidade de realizar operações metalinguísticas", identificada em geral por meio de práticas diagnósticas baseadas em baterias de testes sumários ou descontextualizados, e assim reduzir a metalinguagem a uma função metalinguística é, a nosso ver, um ato de (des)legitimação da linguagem enquanto atividade interacional e sociocognitiva altamente motivada por processos variados (contextuais, semióticos, socioculturais, psicoemocionais, corpóreos etc.), ou seja, um ato náo apenas verbal.

Do mesmo modo, tomar a cognição como resultado da ativação de determinadas faculdades mentais circunscritas à intimidade cerebral é (des)legitimar a existência de processos sociocognitivos variados que constituem a dinâmica funcional e plástica da atividade cerebral, responsáveis tanto pela aquisição e pelo desenvolvimento cognitivo quanto pela reorganizaçáo das atividades mentais. Tais processos, cumpre assinalar, derivados da capacidade humana para a interaçáo, a comunicação, a perspectivação e a recursividade (VYGOTSKY, 1987; LURIA, 1976; TOMASELLO, 1999; CORBALLIS, 2011), como demonstram estudos sobre as relaçóes solidárias entre vida mental e vida social, não se encontram definidos apenas em termos neurobiológicos, nem se encontram confinados às profundezas do cérebro: são dependentes dos processos de significação que se constroem nas práticas sociointerativas.

Outro aspecto da legitimação de determinado metadiscurso científico com impactos não apenas na vida de doentes e seus pares, mas em todo o corpo social (passíveis de serem identificados no protagonismo das indústrias farmacêuticas, nas tecnologias e saberes específicos destinados às patologias crônicas ou incuráveis, no incremento de instituições especializadas etc.) é a que vincula diretamente a doença de Alzheimer com envelhecimento, de forma a não levar em conta a multifatorialidade dessa patologia e a aprofundar uma espécie de patologização da velhice (esta, mais e mais tutelada, vigiada, "ressocializada" 
por normas médicas e institucionais que legitimam "a arte de envelhecer" com resiliência e sucesso e esquecem, ocultam ou deslegitimam sua determinação biológica e suas condiçôes históricas e concretas, conforme Haddad, 2017, p. 86).

O fenômeno da (des)legitimação comunicativa e interacional de indivíduos afásicos ou com diagnóstico de doença de Alzheimer tem uma natureza polimórfica e multimodal; é passível de ser observado, reconhecido e coletivizado por meio de normas que constituem e presidem os regimes simbólicos dos muitos campos sociais (BOURDIEU, 1998) nos quais se exibe, isto é, o campo da ciência, o das comunicaçóes cotidianas (como a conversação), o das práticas médicas, o das ações "inclusivas" etc.

Processos de deslegitimação social em um ou em outro contexto patológico implicam discriminação e exclusão, práticas diagnósticas normativistas, teorizaçóes antiquadas e neurocentristas da sociabilidade humana (ALAIN, 2008), apagamento das condiçóes concretas da vida em favor de uma idealização de caráter (re)educativo a respeito da língua, da comunicação, da inclusão, da saúde.

Nesse cenário, parece-nos importante refletir não apenas sobre o escopo dos dois termos, afasia e doença de Alzheimer, mas também sobre suas implicações (institucionalização, variadas formas de "inclusão social” e esquemas adaptativos aventados pelos indivíduos, seus pares e entorno social).

\section{EXEMPLIFICAÇÃO}

\section{AS AFASIAS: O EL DORADO LINGUÍSTICO EM QUESTÃO}

Uma concepção idealizada de linguagem marca profunda e tradicionalmente o campo de estudos da afasia, definida por Legroux no século XIX como "perversáo da faculdade normal de exprimir ou compreender as ideias pelos signos convencionais" (MORATO, 2009, p. 281). A tradição estruturalista no campo da Linguística e o naturalismo das Ciências Médicas têm, de certo modo, disseminado formulações teóricas que veem na afasia apenas a perda de uma suposta natureza 
adâmica da linguagem, incontaminada pelas imprecisóes e demais "imperfeiçóes" do uso real da língua por indivíduos reais em situaçóes humanas reais. Mais recentemente, estudos de base interacionista e pragmática da linguagem têm reconciliado a linguagem com suas circunstâncias de uso efetivo pelos falantes. Assim, a mudança de escopo do termo linguagem atua no escopo do termo afasia, que passa a ser concebida não apenas como excrescência, como anormalidade, como perda da competência comunicativa e da expressão da racionalidade ("falar bem é pensar bem”):

Hoje sabemos, e isso em função de uma análise menos idealizada da linguagem e dos fenômenos a ela relacionados, que não apenas na afasia há princípios de normalidade (como preconizava já na década de 50 do século XX o russo Jakobson, um dos primeiros a estudar linguisticamente as afasias), como também que as afasias indicam que o "normal" da linguagem não exclui sua radical indeterminação semântica, ou sua aparente incoerência (MORATO, 2000, p. 67).

Longe de dialogar com as concepçóes utópicas de linguagem, centradas em uma espécie de "El Dorado" linguístico (que supóe a existência de uma língua ideal, ou uma língua-teoria infensa aos traços do uso - imprecisos, inexatos, dependentes de vários tipos de contexto - e aos traços da doença - tidos sempre como inesperados, anormais, extravagantes), o estudo da linguagem em uso tem permitido formular perspectivas em que a língua não se encontra descarnada e disjuntada das relaçóes com outros processos cognitivos e com as tramas sociais que dão forma e conteúdo às práticas linguísticas. Nessa perspectiva, as dificuldades nominativas e outras características afásicas não se responsabilizariam, isoladamente, pelos "riscos" comunicacionais que se observam ou se colocam no decurso da interação com afásicos. Também entram no entendimento da dificuldade comunicativa exibida pelo afásico o tipo de recepção social dessa patologia, o comportamento de seus interlocutores ou a qualidade das interaçóes humanas - que podem ser mais ou menos tolerantes, o acolhimento ou náo de semio- 
ses não verbais presentes nos atos comunicativos - como os gestos, as expressóes fisionômicas, a postura corporal, o direcionamento do olhar etc. Todos esses processos semióticos, vale notar, são considerados coexistentes, alternativos e compensatórios na comunicaçáo cotidiana, não apenas de pessoas afásicas. A dimensão multimodal, contextual e funcionalmente dinâmica da interação e da linguagem é, pois, traço legítimo da conversação com afásicos, tanto quanto o é nas práticas daqueles que não têm comprometimento neurológico.

Qualquer ação terapêutica ou educativa que obscureça essa natureza interacional e multimodal da linguagem e da cognição em função de uma visão normativista certamente atuará na deslegitimação de suas propriedades mais constitutivamente humanas:

Se identificarmos a afasia não com a perda de um "constructo ideal incontaminado pela realidade" (afetada pela corporeidade da lesão cerebral), mas sim com uma dimensão empírica da qual o homem e suas circunstâncias não estão removidos, ela - a teorização sobre a afasia - não dialogará mais com as utopias derivadas de proposiçóes abstratas, mas sim com as experiências humanas concretas. Afinal, a linguagem a ser "recuperada" pelos afásicos após os comprometimentos derivados da lesão cerebral em geral é aquela que emerge não apesar da afasia, mas em sua presença (MORATO, 2009, p. 283).

Tomemos, a propósito, um exemplo de construção conjunta do tópico discursivo em uma conversação na qual afásicos e não afásicos que frequentam o Centro de Convivência de Afásicos (CCA), da Universidade Estadual de Campinas (MORATO, 2002), comentam sobre o impacto da afasia na vida cotidiana. A coexistência de semioses, a dinâmica da interação face a face, a atenção conjunta que marca o desenvolvimento da conversação, compartilha e construção de conhecimentos comuns e mútuos atuam na focalização e na progressão do tópico discursivo, bem como no compartilhamento e sedimentação de informações e inferências variadas às quais se lançam os interagentes. Dessa interação participam várias pessoas (afásicas e 
não afásicas). No excerto abaixo, quatro pessoas afásicas trocam informaçóes sobre o momento em que passaram a recuperar a fala após o acidente vascular cerebral:

(a)

MN quantos anos você começou a falar?

MG quantos qu:::e co...meçou a cabalar?

NS FALAR?

((todos os presentes reagem, oral e gestualmente, confirmando a heterocorreção da produção de MG realizada por NS) é::

NS eu sei eu sei... mas eu...

JM [quantos anos... depois... quanto tempo você começou a falar?

NS ai... deixa eu ver...três ano quatro ano...cinco ano...cinco ano

*--.----.----_* ((faz um gesto com a cabeça, olhando para a cima))pa trás eu... não falava nada!

*._-_-* ((movimenta a mão direita para trás do ombro $))$

JM $\quad[$ cinco ah...nada...

Nesse cenário em que a conduta dos interagentes vence o preconceito linguístico - que não tolera a hesitação, o lapso linguístico, a gestualidade, o reparo, a heterocorreção, a reformulação, a variedade linguística - a conversação se torna possível e coloca em relevo o que está em questáo no escopo mesmo do termo afasia: o fato de que as dificuldades de ordem metalinguística não destroem a capacidade discursiva e a coesividade interacional. Além disso, esse cenário permite, ainda, legitimar na prática o que teorias linguísticas de base sociocognitiva e interacionista afirmam sobre a linguagem: que ela não é ideal, que é uma atividade compartilhada, contextualizada e recursiva, que envolve intersubjetividade e perspectivação, que não está encerrada no sistema linguístico e que muitos sáo os processos a ela atinentes, verbais e não verbais.

Vejamos, a propósito, outro trecho de conversação ocorrida no CCA, na qual afásicos e não afásicos discutem a categorização social de pessoas com afasia e a forma pela qual a população leiga (e até mesmo a especializada) tem acesso a conhecimentos sobre essa condição neurolinguística. Nele, CI e MS, afásicos, rejeitam a concepção de afasia enquanto deficiência mental e acusam, nessa confusão conceitual, uma 
recepção social inadequada do conceito de afasia e das reais dificuldades que apresentam os afásicos:
(b)
CI nós temos a mente normal!
MS é!
CI só não temos acesso a... porque as... as pessoas não sabem disso, não sabem, não sabem esse problema... que nós temos.
MC acha que porque (você) não fala...
CI acha que nós temos deficiência mental! Hemiplegia não é deficiência mental! Hemiplegia é... é... do corpo humano! Não é do cérebro!

\section{A CONCEPTUALIZAÇÃO DA DOENÇA DE ALZHEIMER}

Consideremos agora alguns dados encontrados na dissertaçáo de Siman (2015), que desenvolveu um estudo cujo objetivo foi entender como especialistas e leigos que lidam cotidianamente com a doença de Alzheimer a concebem e como suas concepçóes estão ligadas aos dois principais modelos explicativos dessa patologia, o biomédico e o social (1). Os achados de Siman, sob vários aspectos, vão ao encontro dos estudos realizados por Cruz (2008) e Dias (2012).

Em resumo, o modelo biomédico (LYMAN, 1989; LEIBING, 2006), como demonstram os dados coletados por Siman, não apenas ainda influencia fortemente as práticas médicas e terapêuticas e o metadiscurso científico, como dissemina elementos conceptuais que constituem um sistema de referência quase hegemônico, alimentando ou sedimentando determinadas práticas sociais.

Estudos que se interessam por processos que configuram ou ancoram a cognição social, como os que se alinham a estudos sociocognitivos da linguagem (SALOMÃO, 1999; TOMASELLO, 1999; MARCUSCHI, 2002), ajudam-nos a pontuar certas tendências na conceptualização de doenças de uma forma geral. $\mathrm{O}$ que ocorre em relação à conceptualização da doença de Alzheimer inscreve-se aqui. 
Entre essas tendências, é possível destacar um tipo de conceptualização construída metaforicamente, em especial pela personificação da doença de Alzheimer ("a doença como inimigo"), caracterizada na fala das pessoas como um intruso, um ladrão, um algoz, um adversário hostil. Esse tipo de conceptualização parece ancorar estratégias sociais de identificação e contenção do "inimigo", e também de defesa dos que em relação a ele são concebidos como combatentes ou vítimas (doentes, cuidadores familiares). Açóes de legitimação desse posicionamento não são difíceis de serem observadas cotidianamente. $\mathrm{O}$ que nos parece mais complexo aqui é a possibilidade de rompermos com essa conceptualização e deixarmos estruturas conceptuais estereotípicas de lado, como a que concebe o doente e o familiar como vítimas, ou os médicos como heróis destemidos que lutam contra a doença, esse inimigo perigoso ou mortal. Essa conceptualização, vale dizer, também ancora a responsabilidade diagnóstica, os direitos da pessoa com doença de Alzheimer, a organização social (na qual o Estado encontra-se integrado) de "combate" ou convivência com sintomas e implicaçóes da doença.

Como afirmarmos anteriormente (MORATO; SIMAN, 2015), uma das características dos discursos (de natureza figurativa) sobre a doença de Alzheimer é a frequência com que se evocam metáforas de guerra. Vejamos alguns exemplos dessas metáforas na qual o domínio-fonte COMBATE é usado para conceptualizar a doença de Alzheimer como um adversário a ser vencido. O exemplo abaixo, disponível na internet, foi colhido por Siman em sua dissertação (2015):

(c)

Eventualmente, a Doença de Alzheimer mata, mas não sem que antes ela tire tudo de você. Ela rouba as memórias, os julgamentos e a independência das pessoas. Ela rouba os esposos de suas companheiras de vida (...), ela DESTRÓI a segurança das famílias, mas... esta é uma GUERRA QUE PODEMOS VENCER. (Exemplo extraído do site da Associação norte-americana de Doença de Alzheimer) (SIMAN, 2015, p. 36)

Se estão apoiados prioritariamente no modelo biomédico para explicar a doença, especialistas e leigos não deixam de evocar valores do 
modelo social quando falam a respeito do doente. Com efeito, os resultados da pesquisa de Siman, na esteira da discussão sobre os modelos de doença de Alzheimer realizada por Cruz (2008) em sua tese de doutoramento, indicam uma abertura dos entrevistados a certos elementos que integram os modelos sociais de explicação e compreensão da doença, tais como:

- a existência de discrepância entre o desempenho dos indivíduos em diferentes contextos de sua vida cotidiana e os resultados neuropatológicos e neuropsicológicos obtidos em contextos de diagnóstico e de consulta clínica;

- a observação do desempenho cognitivo dos indivíduos em situaçóes interacionais concretas;

- a consideraçáo dos traços psicoemocionais e subjetivos dos doentes e de seus pares;

- a dimensão social do diagnóstico, não redutível à armadura conceitual e metodológica da prática médica ou à decisão isolada do clínico.

Assim, se a concepção neurocêntrica da doença de Alzheimer parece ser ainda fortemente legitimada por práticas e preceitos associados a modelos biomédicos, o discurso de leigos familiares e cuidadores parece abrir-se e legitimar um entendimento de ordem biopsicossocial (isto é, não meramente neurobiológica) da patologia. Nessa perspectiva, que integra aspectos dos modelos social e biomédico, tendência também verificada por Dias (2012), em sua pesquisa de iniciação científica centrada no levantamento de cadeias referenciais da expressão nominal "doença de Alzheimer" na fala de médicos e leigos, os indivíduos diagnosticados não são considerados apenas como mentalmente alienados; com isso, familiares e cuidadores assumem um papel não apenas coadjuvante na interação com eles, ganhando importância no curso da doença e na contenção de sintomas. Ao falar de seus familiares com diagnóstico de doença de Alzheimer afirmam, por exemplo:

(d) [ele] não tem que se adaptar a nós [...]

(e) tem [o direito de saber o que que ela tem[...] 
Contudo, essa abertura se dá principalmente quando fortes traços do modelo biomédico, legitimados socioculturalmente (seja pela concepção essencialmente neurobiológica da doença de Alzheimer, seja pelo protagonismo das Ciências da Saúde nas práticas diagnósticas), não são contrariados. Assim, pelo que foi observado no estudo de Siman (2015), enquanto o modelo biomédico procura, prioritariamente, dar conta da doença, o modelo social é levado a dar conta do doente (e da discussão sobre aspectos socioculturais e psicossociais do processo de envelhecimento, das condiçóes de vida do idoso, da recepção das doenças em nossa sociedade etc.), acentuando-se aqui uma disjunção que nem sempre contribui para uma compreensão abrangente do contexto patológico.

À hora atual é possível perceber que é o foco no doente e em seus pares o fundamento que pode significar algum avanço em relação aos modelos vigentes, seja para questioná-los quando tomados dicotomicamente, seja para construir um modelo alternativo que seja capaz de colocar em relação de reciprocidade processos neurocognitivos e vida social. Contudo, esse avanço parece nascer, também, da contradição que enfraquece o próprio discurso científico, que se baseia no modelo biomédico para explicar a doença e no modelo social para explicar e enfrentar os desafios dela decorrentes.

Tal contradição também parece estar na base dos reais efeitos ou impactos inclusivos da reeducação linguística e comunicativa de afásicos: se, por um lado, busca-se nas atividades terapêuticas diminuir o impacto do estigma contra formas de falar e de se comunicar desses indivíduos, por outro lado essa busca nem sempre parece disposta a açóes de legitimação que visem a mudanças objetivas da realidade histórico-cultural que fornece a base conceptual do estigma, da intolerância e do preconceito linguístico.

\section{CONSIDERAÇÕES FINAIS}

A nosso ver, a ideologia da dominação está presente no naturalismo que rege a prevalência do modelo biomédico na recepção social 
relativa à doença de Alzheimer e à afasia. Não é à toa que as metáforas da guerra e da morte (luto, perda), utilizadas na conceptualização de ambas as doenças, atuam na legitimação do discurso que aponta tanto médicos e terapeutas quanto doentes e familiares como "heróis", deslegitimando, de certo modo, a busca por explicaçóes menos simplistas e dicotômicas. Os dois modelos, na realidade, biomédico e social, permanecem em confronto quanto a alguns pontos essenciais, como, por exemplo, em relação às forças que atuam na legitimação de explicações essencialmente neurobiológicas da doença e do protagonismo de profissionais da Saúde, e em relação às forças que atuam na legitimação da visão do diagnóstico como prática social ou na percepção da doença como uma questão multifatorial.

Contudo, quando o tema é a dominação, percebe-se, hoje, no campo sociológico uma tendência de apontar uma "prevalência", e não propriamente uma hegemonia de determinados valores ou sistemas de crenças - o que coloca em discussão teorias baseadas no conceito de "assimetria ideológica" bourdieusiano. Do mesmo modo, análises de processos de legitimação e deslegitimação no campo linguístico apontam para a direção de uma perspectiva menos naturalista das patologias que afetam linguagem e cognição.

$\mathrm{O}$ incremento de informaçóes sobre a afasia e o impacto das teorias interacionistas, sociocognitivas e discursivas da linguagem e da cognição têm, por outro lado, influenciado as práticas diagnósticas e terapêuticas das patologias linguístico-cognitivas, bem como a compreensão das relaçóes não dicotômicas entre o normal e o patológico (MORATO, 2016).

O debate entre cura e cuidado (CUIJPERS; VAN LENTE, 2015), o desvelamento de discrepâncias entre os comportamentos neuropatológico e cotidiano (CRUZ, 2008), a reflexão crítica sobre as representaçóes socioculturais da doença e do envelhecimento, sobre a "língua legítima” (MORATO; BENTES 2002; MORATO, 2009) e sobre as campanhas de caráter moralista em relação à velhice (HADDAD, 2017) são alguns dos temas que implicam questionamento e mudanças quanto aos processos de (des)legitimação linguístico-cognitiva no campo de patologias como as aqui abordadas. 
Esse cenário reforça a legitimidade social de teses e posicionamentos defendidos por modelos psicossociais de explicação e enfrentamento das afasias e da doença de Alzheimer, bem como atua na contenção de processos de deslegitimação de afásicos e doentes de Alzheimer como seres da comunicação e da interação.

Que a linguagem desempenha um papel importante na questão da dominação e da inequidade social e cognitiva é algo que não podemos desconhecer. Que a linguagem — por si mesma ou isoladamente - é capaz de alterar a ordem do que é legítimo ou não é uma questão em aberto. Contudo, é inegável que o conhecimento sobre processos a que a linguagem faz referência ou ajuda a construir e a desconstruir, como os modelos explicativos de doenças, abre espaço para mudanças epistêmicas e para uma composição de forças mais dinâmica do jogo social.

\section{REFERÊNCIAS}

ALAIN, E. Le cerveau "social": chimère epistemologique et verité sociologique. Esprit, v. 34, p. 79-103, 2008.

ALBUQUERQUE, C.P. Legitimidade e reconhecimento da prática de serviço social. Abordagem construtivista. Serviço Social em Revista, v. 13, n. 2, p. 104-118, 2011.

BAGNO, M. A norma oculta: língua \& poder na sociedade brasileira. 2. ed. São Paulo: Parábola Editorial, 2003.

BLEAKLEY, A. Thinking with metaphors in medicine: the state of the art. Nova York: Routledge, 2016.

BOBBIO, N. Dicionário de Política. Brasília: Editora UnB, 2004.

BOURDIEU, P. A economia das trocas linguísticas: o que falar quer dizer. São Paulo: Edusp, 1998.

CORBALLIS, M. The recursive mind: the origins of human language, thought, and civilization. Princeton: Princeton University Press, 2011. 
CRUZ, F. M. Linguagem, interação e cognição na doença de Alzheimer. Tese (Doutorado) - Instituto de Estudos da Linguagem, Universidade Estadual de Campinas, Campinas, 2008.

CUIJPERS, Y.; VAN LENTE, H. Early diagnostics and Alzheimer's disease: beyond "cure" and "care". Technological Forecasting and Social Change, v. 93, p. 54-67, 2015. https://doi.org/10.1016/j.techfore.2014.03.006

DIAS, T.M. Categorização social e concepção de doença de Alzheimer: implicaçôes e perspectivas dos modelos biomédico e social. Relatório de Iniciação Científica (Fapesp) - Campinas, Universidade Estadual de Campinas, 2012.

FALCONE, K. A legitimação e o processo de categorização social. Veredas, v. 1, p. 16-31, 2011.

FOX, P. From senility to Alzheimer's disease: the rise of the Alzheimer's disease movement. The Milbank Quarterly, v. 67, n. 1, p. 58-102, 1989.

GEORGE, D.R.; WHITEHOUSE, P.J. The war (on terror) on Alzheimer's. Dementia, v. 13, n. 1, p. 120-130, 2014. https://doi. org/10.1177/1471301212451382

HADDAD, E.G.M. A ideologia da velhice. 2. ed. São Paulo: Cortez, 2017.

LEIBING, A. Divided Gazes. In: LEIBING, A.; COHEN, L. (Orgs.). Thinking about dementia: culture, loss, and anthropology of senility. Nova Jersey: Rutgers University Press, 2006. p. 240-268.

LURIA, A.R. Basic problems of Neurolinguistics. Mouton: The Hague, 1976.

LYMAN, K.A. Bringing the social back in: a critique of the biomedicalization of dementia. Gerontologist, v. 29, n. 5, p. 597-605, 1989.

MARCUSCHI, L. A. Do código para a cognição: o processo referencial como atividade criativa. Veredas, v. 6, n. 1, p. 43-62, 2002.

MORATO, E.M. As afasias entre o normal e o patológico: da questão (neuro) linguística à questão social. In: LOPES DA SILVA, F.; MOURA, H. $O$ direito à fala: a questão do preconceito linguístico. Florianópolis: Insular, 2000.

(Org.). Sobre as afasias e os afásicos: subsídios teóricos e práticos elaborados pelo Centro de Convivência de Afásicos. Campinas, Unicamp. 2002.

- Utopias e distopias no campo linguístico: as concepçóes e as teorias sobre as afasias. MORUS - Utopia e Renascimento, n. 6, p. 277-285, 2009. 
- Das relaçóes entre linguagem, cognição e interação - algumas implicaçóes para o campo da saúde. Linguagem em (Dis)curso, v. 16, n. 3, p. 575-590, 2016. http://dx.doi.org/10.1590/1982-4017-160304-0516D

MORATO, E.M.; BENTES, A.C. Das intervençôes de Bourdieu no campo da linguística: reflexôes sobre competência e língua legítima. Horizontes, v. 20, p. 31-48, 2002.

MORATO, E.M.; SIMAN, J. Metáforas da Doença de Alzheimer: entre o metadiscurso científico e a vida cotidiana. Investigaçôes, v. 28, n. 2, p. 1-27, 2015.

PORTER, R. "Expressando sua enfermidade": a linguagem da doença na Inglaterra Georgiana. In: BURKE, P.; PORTER, R. Linguagem, Individuo e sociedade: história social da linguagem. São Paulo: Editora da Universidade Estadual Paulista “Júlio de Mesquita Filho", 1993.

RAJAGOPALAN, K. Sobre o porquê de tanto ódio contra a linguagem "politicamente correta". In: SILVA, F.; MOURA, H. (Orgs.). O direto à fala: a questão do preconceito linguístico. Florianópolis: Insular, 2000. p. 93-102.

SALOMÃO, M.M.M. A questão da construção do sentido e a revisão da agenda dos estudos da linguagem. Veredas, v. 3, n. 1, jan.-jun., p. 61-79, 1999.

SIMAN, J.H. Os frames de Doença de Alzheimer. 156f. Dissertação (Mestrado em Linguística) - Instituto de Estudos da Linguagem, Universidade Estadual de Campinas, Campinas, 2015.

SONTAG, S. A Doença como metáfora: a Aids e suas metáforas. São Paulo: Companhia das Letras, 2007.

TOMASELLO, M. The Cultural Origins of Human Cognition. Harvard: Harvard University Press, 1999.

VAN DIJK, T.A. Discurso e poder. São Paulo: Contexto, 2010.

VYGOTSKY, L.S. Thinking and Speech. Nova York: Plenun Press, 1987. v. 1.

WEBER, M. Economia e sociedade. 4. ed. Brasília: Editora UnB, 2009. v. 1.

ZIMMERMANN, M. Alzheimer's Disease Metaphors as Mirror and Lens to the Stigma of Dementia. Literature and Medicine, v. 35, n. 1, p. 71-97, 2017. https://doi.org/10.1353/lm.2017.0003 


\section{NOTA}

1. "Enquanto o modelo biomédico entende a natureza do declínio cognitivo como neurodegenerativa, o modelo social a entende como socioneurodegenerativa, convocando a um só tempo as influências sociais, psicológicas e cerebrais para explicar tal declínio. Para o modelo biomédico, o diagnóstico é um método neutro e objetivo, enquanto que para o modelo biopsicossocial, trata-se de uma prática socialmente situada e culturalmente sensível (CRUZ, 2008)" (SIMAN, 2015, p. 47).

Recebido em 02 de agosto de 2017.

Aceito em 23 de março de 2018. 